\title{
Real-time histological imaging of a squamous cell carcinoma in situ in the anal canal using endocytoscopy
}

Squamous cell carcinoma (SCC) of the anal canal is rarely diagnosed at an early stage [1]. Endocytoscopy provides ultrahigh magnification, thereby allowing the diagnostic evaluation of structural and nuclear atypia and of the vascular structures of gastrointestinal lesions [2,3]. Endocytoscopy combined with narrowband imaging (EC-NBI) enables a detailed observation of the microvessels [4]. To our knowledge, no studies have previously described the performance of endocytoscopy or EC-NBI for an SCC in situ in the anal canal.

The screening colonoscopy of a 60-yearold asymptomatic woman revealed a slightly elevated $25-\mathrm{mm}$ lesion with scattered reddish spots in the anal canal ( Fig.1a). At 520-fold magnification, EC-NBI (GIF-H290EC; Olympus Medical Systems Corp., Tokyo, Japan) showed abnormal microvessels with differences in caliber, variations in shape, and multiple bends ( $\triangleright$ Fig. 1 b), consistent with the intrapapillary capillary loop patterns observed in esophageal SCC in situ. The lesion was stained with $1 \%$ methylene blue and real-time cellular images were obtained at the same magnification. The cell nuclei appeared as regularly arranged dot-like structures in the normal anal canal mucosa ( Fig.1 c). A significantly increased cellular density, with structure loss, and enlarged nuclei that were heterogeneous in size and shape were observed in the lesion (-Fig.1d; - Video 1). The abovementioned pathological findings from a biopsy would suggest SCC of the anal canal. No obvious metastasis was observed and the lesion was shallow, therefore endoscopic submucosal dissection was performed. Pathological examination confirmed that the resected specimen was an SCC in situ ( Fig. 2).
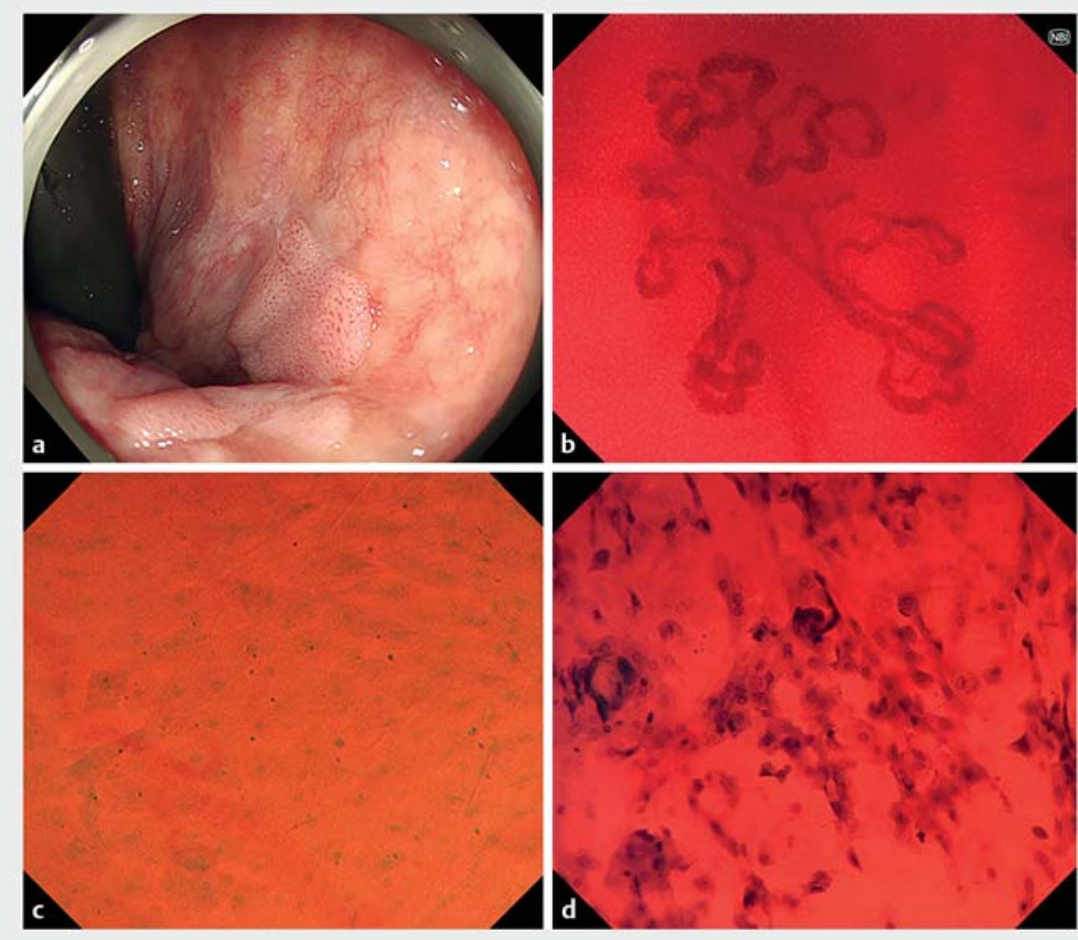

- Fig. 1 Views of a squamous cell carcinoma in the anal canal showing: a on conventional retroflexed view, a slightly elevated lesion with scattered reddish spots in the anal canal; b on endocytoscopy with narrow-band imaging, abnormal microvessels with differences in caliber, variations in shape, multiple bends, and looping; c after staining, on endocytoscopy with white-light imaging, dot-like regularly arranged cell nuclei in the surrounding normal anal canal mucosa; $\mathbf{d}$ after staining, on endocytoscopy of the lesion with white-light imaging, significantly increased cellular density, structure loss, and enlarged nuclei that are heterogeneous in size and shape.

To our knowledge, this is the first report of the use of endocytoscopy for examination of an SCC in situ in the anal canal. We believe that the endocytoscopy findings for such SCCs would be similar to those for esophageal lesions because esophageal lesions also arise from squamous epithelial cells [5]. Future studies are warranted to validate these findings for anal SCC and establish their utility and accuracy.
Endoscopy_UCTN_Code_TTT_1AQ_2AB

\section{Acknowledgments}

We thank Edanz (https://jp.edanz.com/ac) for editing a draft of this manuscript.

\section{Competing interests}

The authors declare that they have no conflict of interest. 


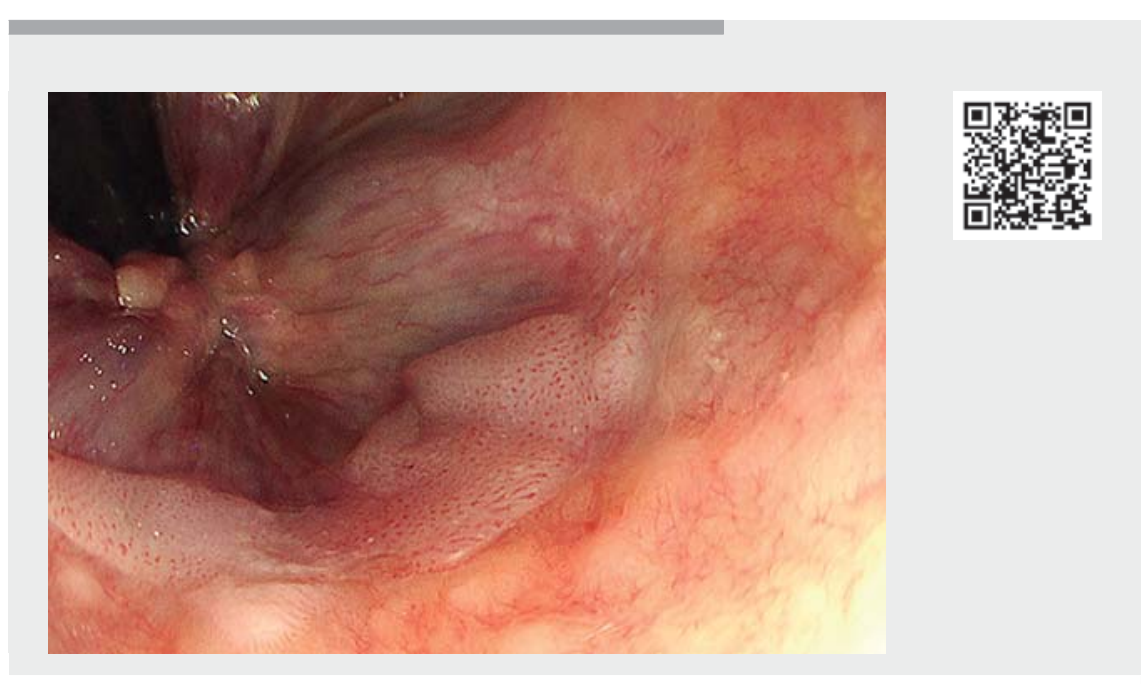

Video 1 A squamous cell carcinoma in situ in the anal canal is observed by endocytoscopy.
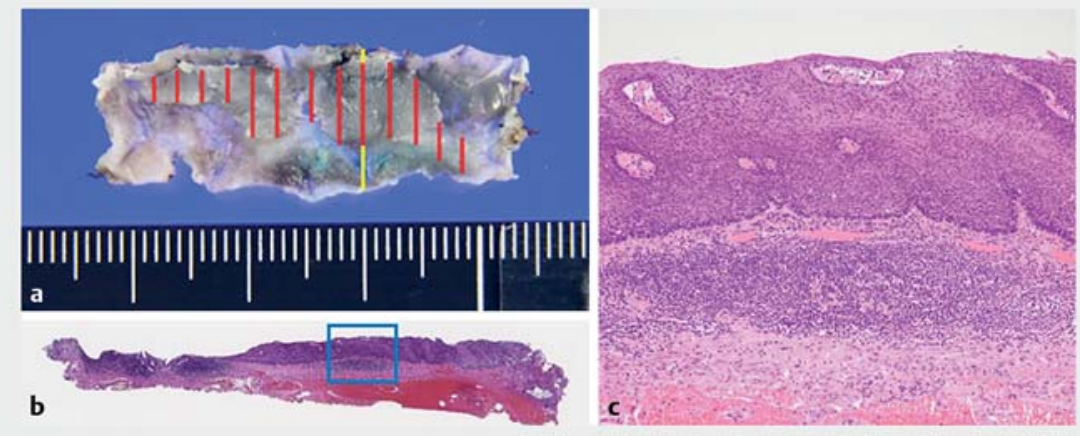

- Fig. 2 Histological findings after endoscopic mucosal resection showing: a the $25 \times 5-\mathrm{mm}$ resected specimen (red lines indicate the area of squamous cell carcinoma in situ); $\mathbf{b}$ the microscopic appearance on hematoxylin and eosin staining (original magnification of the yellow line shown in image a); $c$ atypia of the components of the squamous epithelium in all layers (higher magnification view of the tissue in the blue box from image $\mathbf{b}$ ).

The authors

Manami Utsunomiya', Shigetsugu Tsuji', Azusa Kawasaki ${ }^{1}$, Kenichi Takemura', Kazuyoshi Katayanagi ${ }^{2}$, Hiroshi Minato², Hisashi Doyama ${ }^{1}$

1 Department of Gastroenterology, Ishikawa Prefectural Central Hospital, Kanazawa, Japan

2 Department of Diagnostic Pathology, Ishikawa Prefectural Central Hospital, Kanazawa, Japan
[1] Tsuji S, Doyama H, Yamada S et al. Endoscopic submucosal dissection of a squamous cell carcinoma in situ in the anal canal diagnosed by magnifying endoscopy with narrow-band imaging. Clin J Gastroenterol 2014; 7: 233-237

[2] Sasajima K, Kudo SE, Inoue H et al. Real-time in vivo virtual histology of colorectal lesions when using the endocytoscopy system. Gastrointest Endosc 2006; 63: 1010-1017

[3] Kudo SE, Wakamura K, Ikehara N et al. Diagnosis of colorectal lesions with a novel endocytoscopic classification - a pilot study. Endoscopy 2011; 43: 869-875

[4] Kudo SE, Misawa M, Wada Y et al. Endocytoscopic microvasculature evaluation is a reliable new diagnostic method for colorectal lesions (with video). Gastrointest Endosc 2015; 82: 912-923

[5] Kumagai Y, Monma K, Kawada K. Magnifying chromoendoscopy of the esophagus: in-vivo pathological diagnosis using an endocytoscopy system. Endoscopy 2004; 36: 590594

Bibliography

Endoscopy 2022; 54: E518-E519

DOI 10.1055/a-1655-8401

ISSN 0013-726X

published online 25.10 .2021

(c) 2021. Thieme. All rights reserved.

Georg Thieme Verlag KG, Rüdigerstraße 14, 70469 Stuttgart, Germany

\section{ENDOSCOPY E-VIDEOS}

https://eref.thieme.de/e-videos

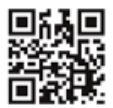

Endoscopy E-Videos is an open access online section, reporting on interesting cases and new techniques in gastroenterological endoscopy. All papers include a high quality video and all contributions are freely accessible online. Processing charges apply (currently EUR 375), discounts and wavers acc. to HINARI are available.

This section has its own submission website at https://mc.manuscriptcentral.com/e-videos 